Illinois State University

ISU ReD: Research and eData

Theses and Dissertations

4-2-2019

\title{
Hip Abductor To Hip Adductor Strength Ratio Measurements In Patients With Non-Specific Low Back Pain
}

Matthew Hugg

Illinois State University, mfhugg19@gmail.com

Follow this and additional works at: https://ir.library.illinoisstate.edu/etd

Part of the Kinesiology Commons

\section{Recommended Citation}

Hugg, Matthew, "Hip Abductor To Hip Adductor Strength Ratio Measurements In Patients With NonSpecific Low Back Pain" (2019). Theses and Dissertations. 1094.

https://ir.library.illinoisstate.edu/etd/1094

This Thesis is brought to you for free and open access by ISU ReD: Research and eData. It has been accepted for inclusion in Theses and Dissertations by an authorized administrator of ISU ReD: Research and eData. For more information, please contact ISUReD@ilstu.edu. 


\section{HIP ABDUCTOR TO HIP ADDUCTOR STRENGTH RATIO MEASUREMENTS IN PATIENTS WITH NON-SPECIFIC LOW BACK PAIN}

\section{MATTHEW HUGG}

36 Pages

Background: The hip musculature is globally known to support the pelvis, which aids in reducing the occurrence of low back pain (LBP). The hip abductors have an important role in stabilizing the pelvis while walking, but previous research has shown a decrease in strength of the hip abductors in patients with LBP. Due to the ability to activate and assist with hip and leg motions, the adductor muscles may have an effect on controlling hip motion to reduce LBP and sacroiliac dysfunction to compensate for weak hip abductors. The hip adductors stabilize the femur during low extremity injuries. However, it is unknown if the hip adductors respond in a similar fashion when pertaining to those with LBP. Objective: To calculate the hip abductor to hip adductor strength ratio in people with and without LBP. Participants: Participants were allocated into either control $(\mathrm{n}=15,179.9 \mathrm{~cm} \pm 8.3,75.6 \mathrm{~kg} \pm 16.0$, age $21.9 \pm 1.8)$ or $\mathrm{LBP}(\mathrm{n}=15$, $169.3 \mathrm{~cm} \pm 9.3,76.2 \mathrm{~kg} \pm 18.5$, age $21.9 \pm 4.3$ ) groups based on the inclusion criteria. The participants in the control group could not have LBP pain as determined with a $0 \%$ on the Oswestry Disability Index (ODI) and 0 on the Visual Analogue Scale (VAS) and were between the age of 18-40. Participants included in the LBP group rated pain as $\geq 3 \mathrm{~cm}$ on the VAS, 20 $40 \%$ on the ODI, met 3 out of 4 of the clinical predictor rules for LBP, and be between the age of 18-40. Those with previous surgeries from the low back and/or lower extremity, a specific diagnosis for LBP (e.g., herniated disc, spondylolysis), or current pregnancy, were excluded 
from the study. Methods: Participants performed a side lying straight leg raise (SLR) for hip adduction and hip abduction of both legs. Participants isometrically contracted at maximal force into a mobilization belt for 5 seconds. The desired range of motion for the SLR was, $10^{\circ}$ of hip adduction and $30^{\circ}$ of hip abduction. A mobilization belt was properly tightened to each participant's degree of motion. Data was recorded using a hand-held dynamometer connected to the mobilization belt to enforce an immoveable object. The highest value of 3 trails was recorded and used in the data analysis. A strength ratio was calculated by dividing hip adductor strength from hip abductor strength for each leg. A ratio greater than 1 indicated stronger hip abductors. A one-way ANOVA was used to assess hip strength ratio differences for each leg between groups. Results: There was no significant difference between LBP and control groups for hip strength ratios on the right $(p=0.785)$ and left limbs $(p=0.237)$. Conclusion: The results of this study did not display any observable or significant difference between the two groups or corresponding ratio measurements. It is still inconclusive what the role the hip adductors play in patients with LBP.

KEYWORDS: dynamometer, mobilization belt, muscle imbalance, straight leg raise 
HIP ABDUCTOR TO HIP ADDUCTOR STRENGTH RATIO MEASUREMENTS IN

PATIENTS WITH NON-SPECIFIC LOW BACK PAIN

MATTHEW HUGG

A Thesis Submitted in Partial

Fulfillment of the Requirements

for the Degree of

MASTER OF SCIENCE

School of Kinesiology and Recreation

ILLINOIS STATE UNIVERSITY

2019 
Copyright 2019 Matthew Hugg 
HIP ABDUCTOR TO HIP ADDUCTOR STRENGTH RATIO MEASUREMENTS IN

PATIENTS WITH NON-SPECIFIC LOW BACK PAIN

MATTHEW HUGG

COMMITTEE MEMBERS:

Noelle Selkow, Chair

Justin Stanek 


\section{ACKNOWLEDGMENTS}

I would first like to thank my primary thesis advisor Dr. Noelle Selkow, Interim Director of the Graduate School and Director of Graduate Athletic Training Education at Illinois State University. With the many tasks she has during a day, Dr. Selkow always set aside time to assist me with my thesis as well as the other students she is advising through this process. She has showed that she is able to bring out the best in many different students, while still maintaining higher standards for all to reach every day. Secondly, I would like to thank Dr. Braden Lawson, an independent athletic trainer, for providing support and wisdom from my undergraduate studies to even today. He has guided me in finding what research I am passionate about. He has always gone above what any mentor would do to ensure my success and reach my fullest potential.

Lastly, I must thank my friends and family who have provided me with the support to continue to better myself so that I may have the prosperous they have set me up to have. This would not have been possible without them. Thank you. 


\section{CONTENTS}

Page

ACKNOWLEDGMENTS

TABLES

FIGURES

CHAPTER I: INTRODUCTION 1

CHAPTER II: LITERATURE REVIEW 3

$\begin{array}{ll}\text { Anatomy } & 3\end{array}$

Anatomy: Bones/Joints 3

Anatomy: Ligaments $\quad 5$

$\begin{array}{ll}\text { Anatomy: Muscles } & 6\end{array}$

$\begin{array}{ll}\text { Low Back Pain } & 10\end{array}$

Non-specific Low Back Pain: Muscular 11

$\begin{array}{ll}\text { Muscle Imbalances } & 14\end{array}$

Non-specific Low Back Pain: Bony 16

$\begin{array}{ll}\text { Specific Low Back Pain } & 17\end{array}$

$\begin{array}{ll}\text { Handheld Dynamometry } & 18\end{array}$

Oswestry Disability Index 19

$\begin{array}{ll}\text { CHAPTER III: METHODS } & 21\end{array}$

$\begin{array}{ll}\text { Design } & 21\end{array}$

$\begin{array}{ll}\text { Participants } & 21\end{array}$

$\begin{array}{ll}\text { Instrumentation } & 22\end{array}$

$\begin{array}{ll}\text { Procedures } & 22\end{array}$ 
$\begin{array}{ll}\text { Data Analysis } & 24\end{array}$

CHAPTER IV: RESULTS 25

CHAPTER V: DISCUSSION 26

$\begin{array}{ll}\text { Limitations } & 27\end{array}$

$\begin{array}{ll}\text { Conclusion } & 28\end{array}$

$\begin{array}{ll}\text { REFERENCES } & 29\end{array}$ 


\section{TABLES}

Table

Page

1. Patient Demographics

2. Strength Ratios

3. Strength Value Averages Normalized to Body Mass 


\section{FIGURES}

Figure $\quad$ Page

$\begin{array}{ll}\text { 1. Hip Adduction } & 24\end{array}$

2. Hip Abduction 24 


\section{CHAPTER I: INTRODUCTION}

The World Health Organization reports low back pain (LBP) as one of the leading causes of disability in the world. ${ }^{1}$ Eighty-five percent of LBP cases are classified as non-specific LBP, meaning that no specific pathology has been diagnosed. ${ }^{2}$ Previous research has identified treatment options for reducing LBP in different populations, such as utilizing strengthening exercises for hip and trunk musculature. ${ }^{3-6}$ Specifically, a need for increased strength in the hip abductors and abdominals has been shown, ${ }^{7-15}$ as well as the effects opposing musculature of the hips and trunk have on LBP when not balanced, including the hamstrings, iliopsoas, quadriceps, and back extensor musculature..$^{8,12,16-19}$ The muscles of the hips and trunk, if overactive or tight, can cause biomechanical changes in the body such as lordosis, kyphosis, and other postural abnormalities. Although research on the causes of non-specific LBP have ended generally inconclusive, ${ }^{20-23}$ researchers and clinicians have found that strengthening the hip and trunk musculature to be beneficial in treating those with LBP. $3,9,24,25$

Muscular strength ratios for patients with LBP have been measured in opposing musculature such as the back extensors and abdominals. ${ }^{26,27}$ The trunk extension/flexion ratio of the low back pain group (men, $0.96 \pm 0.27$; women, $0.77 \pm 0.19$ ) was compared to the non-low back pain group, which demonstrated significantly higher values of $1.23 \pm 0.28$ and $1.00 \pm 0.16$ for men and women, respectively. ${ }^{27}$ A ratio greater than 1.00 indicates greater strength in favor of the trunk extensors, less than 1.00 expresses the ratio showing greater abdominal strength. ${ }^{27}$ This strength ratio was made in participants prospectively followed over five years, which may indicate the continuous weakness of the back extensors over long periods of LBP. However, this contradicts most research in that weak abdominal musculature produces an anterior tilt of the pelvis and increases lumbar lordosis, and that participants with LBP have decreased abdominal 
strength. ${ }^{5,8,12-14,16,23,28}$ Although the hip musculature has been assessed in previous studies, ${ }^{15,23}$ no conclusions were drawn between the difference in strength of the hip adductor and hip abductor muscles in those with and without LBP. In many studies, research has shown a decrease in strength of the hip abductors in patients with LBP. ${ }^{7,9,15,23,29,30}$ There has been no previous research showing a direct relationship between the strength of the hip adductor muscles and LBP.

The hip adductors attach to the pubic symphysis and assist in stabilizing the pelvis. ${ }^{23,31}$ Depending on the joint position, the adductor muscle group can assist with multiple motions at the hip (i.e., flexion, extension and hip rotation). ${ }^{32,33}$ Due to the ability to activate and assist with hip and leg motions, the adductor muscles may have an effect on controlling hip motion to reduce LBP and sacroiliac dysfunction, ${ }^{12}$ if activated properly. The adductors also show increased strength to stabilize the femur following lower leg injuries to compensate for weak abductors. ${ }^{29,34-36}$ However, it is unknown how the hip adductors respond in those with LBP. Therefore, the purpose of this study was to identify the hip abductor to hip adductor strength ratio in patients with LBP compared to those without LBP. Due to previous research of the hip adductor musculature showing increased strength to stabilize the femur in lower leg injuries, we hypothesize the same results will be apparent in the participants with LBP. 


\section{CHAPTER II: LITERATURE REVIEW}

\section{Anatomy}

\section{Anatomy: Bones/Joints}

The major components and relevant bones that articulate within the lower back and hips are the 5 lumbar spine, sacrum, ilium, ischium, pubis, and femur. ${ }^{28,32,37}$ The lumbar vertebrae are composed of multiple structures and landmarks. These landmarks are the spinous process, inferior articular facet, superior articular process transverse process, pedicle, and lamina. ${ }^{38,39}$ The pedicle and lamina are the arching structures connecting in a circle that forms the vertebral foramen. ${ }^{38,39}$ The sacrum shapes the posterior wall of the pelvis with the 5 fused vertebrae it is made up of. ${ }^{38,39}$ These vertebrae (S1-S5) have a small palpable spinous process that are all fused together making the median sacral crest. ${ }^{38,39}$ Other landmarks include the superior articular processes, which articulate with the L5 vertebrae, the sacral foramina for nerves, arteries, and veins to pass through the sacrum, and the lateral articular surfaces so that the sacrum may articulate with the ilium. ${ }^{38,39}$

The pelvic girdle is made up of the ilium, ischium and pubis. ${ }^{38,39}$ The ilium is the most superior bone of the three. ${ }^{38,39}$ There are many important bony landmarks on the ilium that are used for muscle or ligament attachment. The iliac crest is the superior curved aspect of the ilium and serves as a major attachment point for muscles of the hips, legs, and abdomen. ${ }^{37,39}$ The lateral portion of the iliac crest ends at a dull point, the anterior portion is known as the anterior superior iliac spine (ASIS) and the posterior portion known as the posterior superior iliac spine (PSIS). ${ }^{39}$ The ASIS and PSIS are considered major landmarks of the pelvic girdle because many muscles that act upon the pelvis attach at these spines. ${ }^{39}$ Another important landmark of the ilium is the auricular surface. The auricular surface is the portion of the ilium that articulates with the 
sacrum, creating the sacroiliac (SI) joint. ${ }^{38,39}$ This is important for the weight of the body to transmit forces to the spine and pelvis. ${ }^{39}$

The ischium is the posterior-inferior portion of the pelvic girdle. ${ }^{38,39}$ The ischial body is the thicker and superior portion of the ischium that connects to the ilium. ${ }^{38,39}$ The ischial ramus connects to the pubis at the inferior pubic ramus. ${ }^{38,39}$ The ischium has only a few important landmarks the serve as attachment sites for muscles or ligaments in the body. ${ }^{39}$ The ischial spine sits at the posterior medial section of the ischium and is an attachment point for the sacrospinous ligament. ${ }^{39}$ The ischial tuberosity is the posterior inferior portion of the ischium and serves as an origin marker for the hamstring muscles. ${ }^{38,39}$ The ischial tuberosity is also the bone humans use to sit on. ${ }^{39}$

The pubis forms the anterior inferior portion of the pelvis. ${ }^{38,39}$ The pubis is connected to the ilium and ischium at the body of the ilium, and also articulates with the contralateral pubis at the pubic symphysis. ${ }^{39}$ Another important structure for ligamentous connection is the pubic tubercle. This is where the inguinal ligament attaches. ${ }^{38,39}$

The three bones of the pelvis all articulate at one section that creates a depression in the bony structure. ${ }^{38,39}$ The anatomical landmark is known as the acetabulum. ${ }^{38,39}$ The acetabulum serves as the joint structure for the head of the femur to sit in. The femur is the longest bone in the body. Important landmarks for muscle attachment include the greater and lesser trochanter which are lateral and medial to the neck of the femur. ${ }^{38,39}$ The greater and lesser trochanter projections serve as attachment sites for the thigh and gluteal muscles ${ }^{39}$ Posteriorly on the femur, the gluteal tuberosity serves as the main site of attachment for the gluteal muscles. ${ }^{39}$ The gluteal tuberosity continues inferiorly to the mid shaft of the femur. The line is called the linea aspera, which is important for attachment of hamstring and adductor musculature. ${ }^{39}$ The medial 
(or adductor) tubercle at the distal aspect of the femur is the attachment site for the many adductor muscles. ${ }^{39}$ As the lateral epicondyle will serve for the abductor muscles. ${ }^{39}$

\section{Anatomy: Ligaments}

The ligaments of the lumbar spine and pelvis are important for providing the strong stability these bones have while articulating with one another. The major ligamentous anatomical structures relevant to this area are; supraspinous and interspinous ligaments (connecting spinous process to spinous process down the spine), anterior and posterior longitudinal ligaments (runs alongside or inside the spinal canal to provide stability), ligamentum flavum (protects spinal cord and partially covers the facet joint of the spine), intertransverse ligament (connecting between each transverse process), iliolumbar, sacroiliac, sacrospinous and sacrotuberous ligaments. ${ }^{37,38}$

The iliolumbar, sacroiliac, sacrospinous and sacrotuberous ligaments are important for keeping the lumbosacral region of the spine stable on the pelvis. ${ }^{39}$ The iliolumbar ligament attaches to L5 and its transverse process and partially on the L4 transverse process and inserts on the iliac crest. ${ }^{37,39}$ The sacroiliac ligament connects from the depression of the ilium to the posterior sacral body along the sacral crest. ${ }^{37,39}$ This ligament keeps the sacrum stable during nutation and counter-nutation. ${ }^{37,39}$ The sacrospinous ligament runs from the ischial spine to the lateral parts of the sacrum and coccyx. ${ }^{39}$ The sacrospinous ligament supports the sacrum during weight bearing. ${ }^{32}$ The sacrotuberous ligament consists of three large fibrous bands connecting from the inferior portion of the sacrum on the sacral tubercles and inserts on the ischium. ${ }^{37,39}$ It stabilizes against nutation of the sacrum and counteracts against posterior and superior migration of the sacrum during weight bearing. ${ }^{32}$

The hip ligaments consists of the iliofemoral (the y-ligament, limits hyperextension of the hip), pubofemoral (limits abduction), and the ischiofemoral ligaments (limits internal rotation 
and adduction). ${ }^{32,38}$ The iliofemoral ligament has two bands. These bands run from the anterior medial portion of the greater trochanter of the femur, while the lower band begins closer to the lesser trochanter and attaches on the on the ilium supporting the femur at the acetabulum. ${ }^{38,39}$ The pubofemoral ligament is the triangular shaped thickening of the inferior portion of the capsule. ${ }^{39}$ The pubofemoral ligament attaches just lateral to the lesser trochanter to the pubis. ${ }^{38,39}$ The ischiofemoral ligament is the posterior ligament of the capsule spanning from the greater trochanter to the posterior aspect of the ischium and supports the acetabulum. ${ }^{38,39}$ These ligaments help provide structure, give stability, and prevent hypermobility in the spine and hips. $^{37,38}$ Anatomy: Muscles

The hip flexor musculature includes; rectus femoris, vastus medialis, vastus lateralis, vastus intermedius, iliacus, psoas major, and sartorius. ${ }^{37,38}$ The rectus femoris muscles has its origin on the anterior inferior iliac spine and inserts on the tibial tuberosity through the patellar tendon. ${ }^{38}$ The rectus femoris is also innervated by the L4 nerve root by way of the femoral nerve. ${ }^{38}$ The vastus medialis muscle originates on the anteriomedial aspect of the femur, more specifically at the intertrochanteric line. ${ }^{38}$ The insertion of this muscle forms into the patellar tendon and onto the tibial tuberosity. ${ }^{38}$ This muscle is also innervated by the femoral nerve. ${ }^{38}$ The vastus lateralis muscle originates on the greater trochanter of the femur and partially on the lateral aspect of the linea aspera. ${ }^{38}$ The insertion is on the lateral portion of the patella and into the patellar tendon to insert on the tibial tuberosity. ${ }^{2738}$ This muscle will also be innervated by the femoral nerve. ${ }^{38}$ The iliacus and the psoas major, eventually come together to make the iliopsoas muscle. ${ }^{38}$ The iliacus muscle originates at the iliac fossa and inserts on the lesser trochanter of the femur..$^{38}$ The psoas major will also insert onto the lesser trochanter, but its insertion is on the 
anterior portion of the lumbar spine (L1-3), and both of these muscles will be innervated by the femoral nerve. ${ }^{38}$ The sartorius muscle is the longest muscle in the human body and will originate on the lateral aspect of the ASIS. ${ }^{38}$ It runs obliquely across the thigh to the anterior medial aspect where it will eventually become part of the pes anserine and insert on the medial tibial tubercle. ${ }^{38}$ This muscle is innervated by the femoral nerve. ${ }^{38}$

The hip extensor musculature includes the hamstring muscles (semimembranosus, semitendinosus, biceps femoris) and the gluteus maximus. ${ }^{32,37,38}$ The semimembranosus muscle originates on the ischial tuberosity. ${ }^{32,37,38}$ This muscle can have up to 5 insertion points, ${ }^{32,37,38}$ which include the posterior aspect of the medial condyle, the posterior aspect of the tibia, the medial collateral ligament, the arcuate ligament, and the popliteus muscle fascia. ${ }^{32,37,40}$ The semitendinosus muscle has an origin attachment point from the ischial tuberosity region of the pelvis and an insertion attachment point on the upper medial portion of the tibia. ${ }^{38}$

The origin attachment point of the biceps femoris muscle arises as two heads, with the long head from the ischial tuberosity region of the pelvis as a tendon. ${ }^{38}$ The short head of the biceps femoris arises from the outside edged of the linea aspera. The fibers of the short head merge into those of the long head, which then have an insertion attachment point on the head of the fibula. ${ }^{38}$ The hamstring muscles are innervated by the tibial nerve via the sciatic nerve, with the exception of the short head of the biceps femoris that is innervated by the common peroneal nerve. ${ }^{38}$ The gluteus maximus muscle, which is the largest muscle of the body, originates on the posterior surface of the ilium, and the posterior inferior aspects of the sacrum and coccyx, depending on the fibers. ${ }^{38}$ The gluteus maximus inserts on the gluteal tuberosity. ${ }^{38}$ This muscle is innervated by the inferior gluteal nerve, branching from the L5, S1 nerve root. ${ }^{37,38}$ 
The hip abductor musculature includes the gluteus medius and tensor fascia latae/iliotibial band. ${ }^{37,38}$ The abductors have a crucial role in supporting the body during standing and walking, and are considered a postural group of muscles. ${ }^{37,41}$ The gluteus medius muscle originates on the outer surface of the ilium just inferior to the iliac crest and spans most of the outer surface of the ilium. ${ }^{38}$ The insertion for this muscle is on the greater trochanter of the femur. ${ }^{38}$ The superior gluteal nerve between L5-S1 innervates the gluteus medius muscle. ${ }^{38}$ The tensor fascia latae originates on the anterior portion of the iliac crest. ${ }^{38}$ It forms into the iliotibial band as it continues down the lateral thigh. ${ }^{38}$ The iliotibial band inserts on the lateral condyle of the tibia and is innervated by the superior gluteal nerve. ${ }^{38}$

The hip adductors include; adductor magnus, adductor longus, adductor brevis, pectineus and gracilis. ${ }^{37,38}$ These muscles all adduct the hip, while some also flex or extend the hip. The hip adductor musculature all originates on the pubis and inserts on various portions of the posterior and/or medial aspect of the femur. ${ }^{38}$ The adductor magnus is split into two heads, the oblique head, originating on the inferior ramus of the pubis and inserting on the gluteal tuberosity, linea aspera and proximal supracondylar line of femur. ${ }^{38}$ The vertical head of the adductor magnus originates on the ischial tuberosity and inserts on the adductor tubercle. ${ }^{38}$ The oblique head of the adductor magnus is innervated by the obturator nerve, while the vertical head is innervated by the sciatic nerve. ${ }^{37,38}$ The adductor longus originates on the superior portion of the pubis and inserts on the middle third of the linea aspera. ${ }^{38}$ The adductor longus is innervated by the obturator nerve. ${ }^{38}$ The adductor brevis muscle originates on the lateral surface of the pubis and inserts on the proximal portion of the linea aspera. ${ }^{38}$ This muscle is also innervated by the obturator nerve. ${ }^{38}$ The pectineus muscle originates on the pectineal line, along the superior ramus of the pubis and inserts on the posterior surface of the femur, just inferior to the lesser 
trochanter. ${ }^{38}$ The pectineus is innervated by the femoral nerve. The gracilis muscle originates on the inferior surface of the pubis, just lateral of the pubic symphysis. ${ }^{38}$ The insertion of the gracilis muscle becomes part of the pes anserine and attaches onto the proximal medial tibia. ${ }^{38}$ The muscle is innervated by the obturator nerve. ${ }^{38}$

Moving away from muscles that act on the hip, the abdominal musculature is important for spinal stability and the transfer of forces from the pelvis. The abdominal musculature consists of; rectus abdominus, transversus abdominis, and internal and external oblique. ${ }^{37,38}$ The rectus abdominus muscle originates on the superior edge of the pubis and pubic symphysis and inserts on the costal cartilage of ribs 5-7, and partially on the xiphoid process. ${ }^{38}$ The rectus abdominus is innervated by the lower intercostal nerves. ${ }^{38}$ The transversus abdominis muscle has multiple origin points due to the muscle wrapping around the body. The origin points are the inner surfaces of the lower six ribs, thoracolumbar fascia, iliac crest, and the inguinal ligament. ${ }^{38}$ The insertion is on the linea alba. ${ }^{38}$ Since this muscle spans so much of the body it is innervated by multiple nerves. ${ }^{38}$ The nerve innervations include the 7-12 intercostal, iliohyogastric, and ilioinguinal nerves. ${ }^{38}$ The internal oblique originates on the anterior iliac crest, the inguinal ligament, and the thoracolumbar fascia, while its insertion is on the linea alba and the costal cartilage of the lower five ribs. ${ }^{38}$ Much like the transverse abdominus, the internal oblique muscle is innervated by the $8-12$ intercostal nerves, iliohyogastic, and ilioinguinal nerves. ${ }^{38}$ The external oblique originates on the external surfaces of ribs 5-12 and inserts on the iliac crest and the linea alba. ${ }^{38}$ The external and internal oblique muscles are innervated by the same nerves. ${ }^{38}$

The back-extensor muscles include; quadratus lumborum, iliocostalis, multifidus, and spinalis. ${ }^{37,38}$ The action these muscles perform is trunk/back extension and some muscles may assist in trunk rotation. ${ }^{32,37}$ The quadratus lumborum muscle originates on the posterior iliac crest 
and the iliolumbar ligament, and inserts on the transverse processes of L1-L4. ${ }^{38}$ This muscle is innervated by the lumbar spinal nerves. ${ }^{38}$ The iliocostalis originates on the sacrum and the medial portion of the iliac crest and inserts on the outer surface of the lower six ribs. ${ }^{38}$ This muscle is innervated by the thoracic and lumbar spinal nerves. ${ }^{38}$ The multifidus spans the all way up the spine attaching onto each spinous process, and originates on the posterior sacrum, superior iliac spine, mammillary processes of lumbar vertebrae, and transverse processes of the thoracic vertebrae. ${ }^{38}$ This muscle is innervated by the spinal nerves at each vertebral level. ${ }^{37,38}$ The spinalis muscle originates on the spinous processes of T10-L3 and inserts on the spinous processes of $\mathrm{T} 1-\mathrm{T} 8 .^{38}$ This muscle is innervated by the dorsal rami of the thoracic and lumbar spinal nerves. ${ }^{38}$

\section{Low Back Pain}

The World Health Organization reports low back pain (LBP) as one of the leading causes

of disability in the world. ${ }^{1}$ Lifetime prevalence of LBP has been reported to be as high as $84 \% .{ }^{42}$ Of these patients, approximately $85 \%$ are classified as non-specific LBP, meaning that no specific pathology is causing the pain. ${ }^{2}$ Although it is difficult to follow due to differentiating criteria on what a recurrence of LBP is, studies have shown that the recurrence rate for episodes of LBP can be anywhere between $25-74 \% .{ }^{43-45}$ Previous research has attempted to present treatment for reducing LBP in different populations, however due to extensive confounders, research is generally inconclusive. However, there is exponential progress in understanding what treatments should be administered to patients with LBP. By using clinical prediction rules (CPRs), ${ }^{46}$ a practicing clinician may determine what intervention could be effective for improving care. ${ }^{46,47}$ While using the CPR, the clinician is able to determine whether a patient is to be treated using spinal manipulation, stabilization exercises, or mechanical traction treatment 
achieve a high clinical outcome. ${ }^{46,48}$ The CPRs for preliminary prediction rule for success with stabilization treatment contains 4 variables: positive prone instability test, aberrant movements present, average SLR greater than $91^{\circ}$, and age greater than 40 years old. ${ }^{47,49}$ It is suggested that the observation of aberrant movement patterns during active trunk motion is valuable in the diagnosis of lumbar segmental instability. ${ }^{49}$ The presence of aberrant movements may represent an inability to adequately control lumbar motion and indicate a need for stabilization exercises. ${ }^{49}$ Non-specific Low Back Pain: Muscular

Over the years, researchers have conducted many experiments to understand the effects of the muscular anatomy in the back and hips in order to find a solution for those suffering with LBP. ${ }^{8,9,12,14,50-52}$ Due to muscular origin and insertion of several muscles on the pelvis, it has been shown that tight and weak musculature can disrupt the normal positioning of the pelvis. ${ }^{50,51,53}$ As the pelvis moves during activity, the musculature attaching onto the pelvis and lumbar spine must all accommodate in order to have fluid motion. While an agonist muscle is creating an action, (i.e. the hip flexors flexing the hip to walk forward), the antagonist muscle (hamstrings and gluteals) must also fire to keep the pelvis symmetrical and stabilized. ${ }^{21}$ When the agonist and antagonist muscle have an imbalance in tightness or strength, pelvic obliquity and postural abnormalities occur., ${ }^{9,21,22,54}$ The hip flexor muscle group would create an anterior tilt of the pelvis, creating more lumber lordosis, which can lead to LBP. ${ }^{4,28}$ Throughout multiple research studies assessing the hip flexors and the relationship to LBP, no significant association between hip flexor muscle length and lumbar lordosis or LBP have been found. ${ }^{21-23,55}$ There are records however, showing that the strength of the hip flexors muscles has an effect on LBP. ${ }^{23}$ These results suggest that subjects with weaker hip flexor muscles had LBP compared to healthy subjects. ${ }^{23}$ 
In many cases and studies on LBP, one of the most common findings is that the subjects with LBP have hamstring tightness. ${ }^{4,16,17,28}$ Hamstring tightness causes a posterior pelvic tilt to occur, which decreases lumbar lordosis, leading to LBP., ${ }^{4,16,17,28}$ By decreasing lumbar lordosis to a significant amount, the lumbar spine begins to lose its lordotic curve. ${ }^{56}$ This places more pressure on the vertebrae and alter normal postural alignment. ${ }^{56}$ Having restricted range of motion of the hamstrings, subsequently increases stiffness of the low back. ${ }^{56}$ Although many studies discuss how hamstring tightness will lead to LBP, there have been few studies that contradict this finding. ${ }^{20,23}$ Other researchers believe that there is no association of hamstring tightness on LBP, but that the hamstring tightness is a compensatory mechanism for pelvic instability. ${ }^{20,21,23,57}$

A major contributor to LBP is the strength of the abdominal muscles. It is supported that weak abdominal musculature produces an anterior tilt of the pelvis and increases lumbar lordosis, and that subjects with LBP have decreased abdominal strength. ${ }^{5,8,12-14,16,23,28}$ Although multiple studies have shown the importance of abdominal strength, there have also been many articles stating the opposite, that abdominal muscle strength has no association on lumbar lordosis or pelvic inclination in subjects both with and without LBP. ${ }^{6,22,23,50,58}$

The back-extensor muscles are important for activities of daily living. Most of these muscles are prime stabilizers in supporting body weight and keeping balance of the body while standing and walking or performing other physical activities. ${ }^{26,28,53,59}$ Since the back extensor musculature is used quite frequently, it is hypothesized that back extensor endurance is a major component to LBP. This theory has been supported by researchers showing similar results in that subjects with LBP have shown decreased muscle endurance. ${ }^{60,61}$ Due to decreased muscle 
endurance, the muscles fatigue quicker and overload the soft tissues and other structures of the lumbar spine. ${ }^{8,28,55,60-63}$

Previous researchers have classified these back-extensor muscles as prime stabilizers in supporting the body, which tend to shorten with overstress and back pain. ${ }^{64}$ For this reason, flexibility within the back extensor muscles is also an important component to LBP. Lack of flexibility and tightness of the back extensor muscles has been studied and shown in patients with LBP. ${ }^{18,19,23,65,66}$ The ability of the back extensor muscles to effect the positioning of the lumbar spine explains why other muscles attaching to the spine or pelvis are important for stabilization of the body and getting a normal posture. ${ }^{17,59}$

The hip abductor muscles are essential in the stabilization and movement of the pelvis. ${ }^{15}$ This is especially important when transferring forces from a two-legged to one-legged stance..$^{34,35,41}$ While standing, the role of the hip abductors is to keep the pelvis horizontal and equal to its contralateral side. ${ }^{32,37}$ The abductor muscles can cause a cascade of effects to the body biomechanically that can cause LBP. It has been shown in countless studies, that in subjects with LBP, the abductor muscles are extremely weak on the affected side or both sides in these patients. ${ }^{4,9,12,15,25,29,36,51}$ The weakness of the hip abductors causes the pelvis to drop ${ }^{15}$ and changes the way the innominate sits within the sacrum and the spine. ${ }^{59}$ This biomechanical change may cause LBP. The research conducted on the hip abductors for LBP has been extensive, with most concluding that strengthening exercises for the hip abductors is beneficial for treating those with LBP. ${ }^{2-4,8,9,12,15,16,25,28,41,64,67}$

The hip adductors are crucial during gait. These muscles fire continuously during the midstance transition of walking to stabilize the femur. ${ }^{34,35}$ As beneficial as this is, it may become problematic if there is a patient with LBP. Described in the previous paragraph, we understand 
that a patient with LBP has less firing and weakness of the gluteus medius and other hip abductors muscles. 4,9,15,25,29,36,51 This weakness does not help support the femur during gait, which will allow the femur to fall or collapse into uncontrolled adduction during movement. ${ }^{68}$ The hip adductors do play a significant role in lateral pelvic stability. ${ }^{12}$ Imbalances of these muscles can create pelvic obliquity. ${ }^{12}$ The adductors have also been hypothesized to assist which sacroiliac pain, however, the effect of the hip adductors has never been directly assessed on LBP. ${ }^{12,23}$ Nourbakhsh ${ }^{23}$ observed the hip adductors in participants with LBP, simultaneously measuring all core and extremity musculature. The results showed the hip adductors to be taken out of the regression model, however, they did show that the hip adductors are significantly correlated to changing in strength output when surrounding musculature is affected. ${ }^{23}$ The hip adductors have been examined in regards to pain at the hip, knee, foot, and other overuse injuries. ${ }^{7,29-31}$ These studies showed the hip adductors needing strengthening to reduce the risk of strains or increase support at the knee. Few studies however, described the role of the hip adductors in supporting the whole body during activities such as walking, running and sprinting. ${ }^{34,35,68}$ When observing patients with overuse injuries of the knee, hip, and foot, the hip abductors were found to be weak and lack firing on the affected leg. ${ }^{29,68}$ As pointed out in this article, the hip adductors on the injured leg were significantly stronger than the uninjured side adductors. $^{29}$

\section{Muscle Imbalances}

In many cases, muscle imbalances have been studied in observing a patient's posture, and determining the effect the core and surrounding musculature have on posture. ${ }^{22,28,64}$ Most clinicians would expect that if a patient was standing with excessive lumber lordosis, the initial thought would be that this patient has weak abdominal musculature. ${ }^{22,28}$ They may also predict 
that the patient's erector spinae and hip flexor muscles were tight. ${ }^{22,64}$ This causes an increased anterior tilt of the pelvis and exaggerates lumbar lordosis. ${ }^{22}$ These ideologies describe that an agonist musculature may be weak and that the antagonist muscle would either be short or tight.

\section{Quadriceps \& Hamstrings}

The quadriceps and hamstring muscles effect the hips due to their attachment on the pelvis. The quadriceps attachment on the anterior aspect and hamstrings on the posterior aspect of the hips, control which way the hips move. ${ }^{32}$ The quadriceps and hamstring are constantly pulling in the direction that the muscle fibers run. However, there must be balance between these muscles in order to keep the body in its natural positioning. While observing the body in pathological conditions, as opposed to normal conditions, Steindler ${ }^{69}$ observed the concentric quadriceps (Qcon) and concentric hamstring (Hcon) strength in order to determine differences in the body biomechanically that are introduced with a pathological condition such as LBP. The generalization is that absolute knee extension muscle force should exceed knee flexion force by a magnitude of 3:2 i.e. Hcon/Qcon of $0.66 .{ }^{69}$ Values ranging from $0.43-0.90$ for this knee flexorextensor ratio have been reported. ${ }^{69}$ A 'normal' Hcon/Qcon ratio of 0.6 is frequently used as an injury prevention and rehabilitation tool. ${ }^{70,71} \mathrm{~A}$ higher $\mathrm{H} / \mathrm{Q}$ ratio would represent greater balance, and of particular interest would be considering the eccentric hamstring (Hecc) contraction to Qcon, due to the high quadriceps moment production observed during knee extension. An Hecc/Qcon ratio of 1.0 would be the recommendation. ${ }^{72}$

\section{Back Extensors \& Abdominals}

Researchers have studied the effects of the back extensor muscles and abdominal muscles when evaluating the relationship to LBP. It has been shown that increased lumbar lordosis and weak abdominal muscle force show a link to the contribution of LBP. ${ }^{54,73}$ In one study, the 
extension/flexion ratio of the low back pain group (men, $0.96+/-0.27$; women, $0.77+/-0.19$ ) was compared to the non-low back pain group, which demonstrated significantly higher values of $1.23+/-0.28$ and $1.00+/-0.16$ for men and women. ${ }^{27}$ These findings support the hypothesis that the abdominals become weak during incidents of LBP and can cause increased lumbar lordosis. It has also been shown that patients with LBP have approximately $60 \%$ of absolute trunk strength compared to healthy participants. ${ }^{13}$ While in this study the patients were evaluated based on their own specific strength ratio measurements, the ratios showed that the patients had attempted extension strengths that were significantly less than their strengths in the other types of movements tested. ${ }^{13}$

\section{Abductors \& Adductors}

The natural hip adductor to abductor strength ratio is approximately $1.4 \mathrm{rad} / \mathrm{s}$, showing that the adductors output slightly more force. ${ }^{74}$ The hip adductor and abductor muscles play an essential role in lateral pelvic stability. ${ }^{12}$ A muscle imbalance between these two muscle groups, due to either muscle weakness or tightness, can cause pelvic obliquity resulting in LBP. ${ }^{15}$ It has been shown that the hip abductor muscles weaken when LBP is present, ${ }^{9,15}$ but the effects of the adductors have only been studied at the knee when the abductors become weak. These results shown that the adductors actually increase in strength and force output. ${ }^{29}$ It is hypothesized that this occurs in order to stabilize the femur for the surrounding musculature. ${ }^{31,34,35}$ However, it is unclear how the hip abductor to adductor strength in those with LBP compare to healthy participants.

Non-specific Low Back Pain: Bony

A major factor to causing LBP can be lumbar lordosis. Studies have shown that subjects with increased lumbar lordosis experience more pain, however, the size of the lordotic curvature 
has no relationship on the development of LBP. ${ }^{22,53,75-77}$ Usually associated with lumber lordosis, is sacral inclination. Studies have found that patients that suffer with LBP caused by lumber lordosis also have a certain degree of sacral inclination. The degree of sacral inclination is associated with the amount of curvature in lumber lordosis. ${ }^{78,79}$ This increased amount of lumbar lordosis and sacral inclination alters postural positioning that causes people to put more stress on the lumbar spine, creating pain.

Lumbar lordosis may also be affected by the tilt in one's pelvis. As the back and legs move, so does the pelvis. As the lumbar spine is moved into more lordosis, typically the pelvis will increase its inclination and move into an anterior rotation. Changes in pelvic inclination have been speculated to increase lumbar lordosis and cause LBP. ${ }^{4,16,28}$ In multiple studies regarding the amount of anterior tilt and pelvic inclination, results have shown that there are significant changes in pelvic inclination and the relation of this angle to healthy asymptomatic subjects and subjects with LBP. ${ }^{53,75,80}$

\section{Specific Low Back Pain}

Approximately $5-15 \%$ of LBP can be attributed to a specific cause such as an osteoporotic fracture, neoplasm or infection. ${ }^{81}$ With many anatomical structures in the low back and hips, there is always the possibility of acquiring LBP through a specific condition. Examples of these include fractures, spondylosis, spondylothesis, disc herniations, and congenital defects.

Specific LBP can also occur when the body's alignment is changed, which is typically congenital. Without pelvic stabilization, the pelvis has increased mobility, which may lead to pelvic malalignment and can cause LBP. ${ }^{53,82,83}$ Leg length discrepancy or inequality has been shown to cause LBP, lateral pelvic inclination and lumbar scoliosis. ${ }^{82}$ It is believed that a leg length discrepancy may cause changes in the orientation of the innominate. This results in 
rotation of the innominate anteriorly on the shorter leg and posteriorly on the longer leg. ${ }^{84}$ This innominate rotation is thought to create a sacral tilt, which affects the articulation of the lumbosacral joint. ${ }^{84}$

\section{Handheld Dynamometry}

A Handheld Dynamometer (HHD) is an instrument used to quantify and give an objective measurement to muscle force production. ${ }^{85}$ In multiple studies, when using a HHD on lower extremity muscles, the intrarater and interrater reliability is considered high $(0.90-$ 0.99). ${ }^{12,85-87}$ The issues that clinicians may run in to when using a HHD is measuring musculature that could be very strong. This may cause the researchers hand to move due to the amount of force needed to resist the participant. To combat this, a belt may be used to fixate the arm and the hand if necessary and reliable and valid results of HHD can still be created. ${ }^{85,87}$ By increasing the stabilization of the hand measuring the lower extremity there is less error to occur.

To measure of the adductor and abductor muscles, the subject must perform a motion that will elicit force coming singularly from these muscle groups as possible. These have been determined through the side-lying straight leg raise for adduction(SLRAD) motion generating the most isolated contraction of most adductor muscles. ${ }^{88}$ Side-lying straight leg raise for abduction (SLRAB) has also been shown to demonstrate high activity of the gluteus medius and abductor muscles when performing the SLRAB and creating more isolation to this musculature. ${ }^{67}$ This motion also limits the activation or involvement of surrounding muscles such as the gluteus maximus. ${ }^{67}$

In order to normalize strength measurement data according to body mass (BM) and sex, the following recommendation has been applied. normalizing force to $\mathrm{BM}$ and torque to $\mathrm{BMxH} .{ }^{89}$ It is an effective ratio standard method of removing body-size dependence for all hip 
strength measures. ${ }^{89}$ Also, normalizing hip strength to BM with the experimentally observed allometric b-values (bmusc or bavg) also allows for body-size-independent measures ${ }^{89} \mathrm{BMxH}$ may be appropriate for removing body-size dependence in nonathletic, heterogeneous populations. However, using the validated sex-specific bavg values for force (men, .554; women, .335 ) and torque (men, .792; women, .482) is recommended for the normalization of hip strength. ${ }^{89}$

Using body-size-independent normalization techniques also allows for more appropriate comparisons of results, which will produce a more consistency ${ }^{89}$ Ratio standard normalization of hip strength force by BM. ${ }^{89}$ Oswestry Disability Index

The Oswestry Disability Index (ODI) is a condition-specific outcome measurement tool used to identify limited functionality in patients and the severity of LBP. ${ }^{90}$ The test is considered the 'gold standard' of low back functional outcome tools. ${ }^{90}$ The ODI uses a graded scoring system in order to determine the severity of pain and functionality in patients completing the survey.$^{90}$ The grading survey allows the participants to pick a statement that most relates to the way they feel, the scores being $0-5,0$ being the subject does not experience pain or limit in function, 5 being the subject is in intense pain and cannot perform any function of movement comfortably. ${ }^{90}$ The sections of the ODI are; pain intensity, personal care, lifting, walking, sitting, standing, sleeping, sex life, social life, and travelling. ${ }^{90}$ After the subject grades each section, the scores are added up. This combined total is then converted into a percentage score, by multiplying by 100 . The percentage score provides the severity and amount of disability the patient is experiencing for the clinician to objectively understand. The severity percentages are 0 $20 \%$, indicating minimal disability. ${ }^{90}$ Subjects with minimal disability can cope with most living 
activities, usually no treatment is needed ${ }^{90}$ Moderate disability (21-40\%) indicates these patients experience pain with most functions of lifting, standing, and walking, but are able to easily perform activities of daily living. ${ }^{90}$ Severe disability (41-60\%) indicates pain remains the main problem in this group, but activities of daily living are affected. ${ }^{90}$ These patients require a detailed investigation. Those that score $61-80 \%$ indicates the patient is crippled, back pain impinges on all aspects of the patient's life and a score of $81-100 \%$ indicates that these patients are bed bound. ${ }^{90}$ 


\section{CHAPTER III: METHODS}

\section{Design}

This was a descriptive laboratory study, utilizing a cross-sectional measure of the hip abductor and hip adductor force production to create a strength ratio between the two muscles. Participants were randomized into control or LBP groups based on inclusion and exclusion criteria. Randomization and assessment of the participants was done by a second researcher. The researcher performing all strength measures was blinded to group allocation. In both groups, the maximal force production of the hip abductors and hip adductors on both legs was measured to evaluate differences between groups.

\section{Participants}

Thirty participants volunteered to be a part of this study (Table 1). Exclusion criteria included a specific diagnosis resulting in LBP, previous surgeries to the back or lower extremity, pregnancy, or a score $<20 \%$ or $>40 \%$ on the Oswestry Disability Index (ODI). Participants signed the University's approved informed consent to participate in this study. Inclusion criteria for this study included participants between the ages of 18-40 with non-specific LBP, a Visual Analogue scale (VAS) of $\geq 3 \mathrm{~cm}$, and scores between $20-40 \%$ on the ODI. This ODI scoring, indicates that the participant experiences moderate disability when attempting to complete activities of daily living (ADL; i.e., sitting, standing, lifting objects) ${ }^{91}$ Participants were also given a 4-item checklist using clinical predictor rules (CPR) to assess participants with LBP to be included in the study. ${ }^{47}$ The participants needed to fulfill 3 out of the 4 criteria: having $<90^{\circ}$ of an active SLR, positive prone instability test, present aberrant movements, and being less than 40 years of age. ${ }^{48,49}$ The participants in the control group completed the same questionnaires, and needed to score $0 \%$ on the ODI and 0 for VAS. 
Table 1

Participant Demographics

\begin{tabular}{|c|c|c|c|c|c|c|}
\hline & Height $(\mathrm{cm})$ & Weight $(\mathrm{kg})$ & Sex & Age (years) & ODI (\%) & VAS (cm) \\
\hline $\begin{array}{c}\text { LBP } \\
\mathrm{n}=15\end{array}$ & $169.3 \mathrm{~cm} \pm 9.3$ & $76.2 \mathrm{~kg} \pm 18.5$ & $9 \mathrm{~F}, 6 \mathrm{M}$ & $21.9 \pm 4.3$ & $22.3 \pm 4.1$ & $3.9 \pm 0.8$ \\
\hline $\begin{array}{c}\text { Control } \\
\mathrm{n}=15\end{array}$ & $179.9 \mathrm{~cm} \pm 8.3$ & $75.6 \mathrm{~kg} \pm 16.0$ & $7 \mathrm{~F}, 8 \mathrm{M}$ & $21.9 \pm 1.8$ & 0 & 0 \\
\hline
\end{tabular}

Note. This table displays the participant demographic for both the Control and LBP groups.

\section{Instrumentation}

All participants completed an ODI ${ }^{90,92}$ and a VAS. ${ }^{93}$ The ODI is considered the 'gold standard' of low back functional outcome tools. ${ }^{90}$ A change of $12.8 \%$ is considered the minimal detectable change for changes in disability. ${ }^{94}$ The VAS quantifies subjective pain using a $100 \mathrm{~cm}$ line with only the end points labeled as "no pain" and "worst pain". 93 A minimal clinical difference for the VAS is $9-10 \mathrm{~mm} .^{95}$

To measure muscle strength of both the hip adductor and hip abductor muscle groups, a hand-held dynamometer (HHD; Lafayette Manual Muscle Tester Model 01163) with a strap was implemented. Using a HHD has been shown to be a reliable measure when recording results for strength in the hip abductors and hip adductors. ${ }^{85}$

\section{Procedures}

Each participant had strength measurements recorded for the hip adductors and hip abductors on both legs. Using the HHD, the rater taking the measurements would apply the HHD at the distal third of the femur. ${ }^{39,88}$ For the hip abductors, measurements were taken at the lateral distal third of the femur. ${ }^{39,86}$ The HHD was connected to a non-elastic mobilization belt, allowing for maximal contraction to occur into an immovable object. The participant was brought to $30^{\circ}$ of hip abduction, which removed any slack from the strap. For hip adduction the 
participants were brought to $10^{\circ}$ of hip adduction. ${ }^{96}$ The action that the participants completed for both hip adductors and hip abductors was a side-lying straight leg raise (SLR). The SLR exercise was picked as the manual muscle test to be performed due to highest activation of the hip adductor and abductor muscle groups. ${ }^{67,88}$

Participants were shown both positions and instructed on how to perform the movements correctly. The participants were allowed to practice no more than three times before data collection, in order to familiarize themselves with the action without creating fatigue. The order of the testing positions was performed randomly.

Participants performed the side-lying SLR $^{88}$ for the hip adductors (SLRAD: Figure 1) was lying on the same side as the adductor muscle group being tested. The non-testing hip and knee were flexed and rotated so that the foot was flat on the table in front of the leg being tested. The leg being tested was kept straight throughout the movement while the participant adducted up towards the ceiling.

The participants completed the side-lying SLR for the hip abductors ${ }^{87}$ (SLRAB: Figure 2) lying on the opposite side as the abductor muscle group being tested. The non-testing leg was straight on the table in line with the rest of the body. The leg being tested was kept straight throughout the movement while the participant abducted up towards the ceiling.

For each muscle group on both legs, the movement was performed and measured three times each, each contraction was held at maximal effort by the participant for five seconds. Before the next test was performed, the participants were given a minimum of five seconds to relax. The researcher asked each participant before the manual muscle test, "Are you ready?". At that time the next test was performed. All three measurements were recorded, using the highest recorded measurements as the participant's force for that muscle group. 


\section{Data Analysis}

A total of 42 participants were assessed for inclusion criteria. Twelve participants were excluded from the study due to not fulfilling all requirements of the inclusion criteria. This included participants that did not display or report $20 \%-40 \%$ on the ODI, or $<3 \mathrm{~cm}$ on the VAS. The measurements of hip adductor and hip abductor strength were normalized using a ratio, similar to the activation ratio of the transversus abdominis bilaterally. ${ }^{97}$ The strength ratio measurement was calculated by taking hip abduction strength/hip adduction strength. A ratio > than 1 indicated that the hip abductors were the stronger muscle group of the leg being measured. A one-way ANOVA was run to assess differences in hip strength ratio between people with and without a history of LBP.

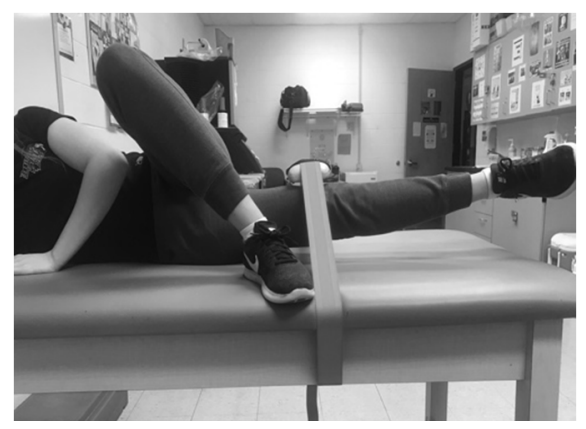

Figure 1. Hip adduction. The mobilization belt adjusted to $10^{\circ}$ of motion. Participant adducts.

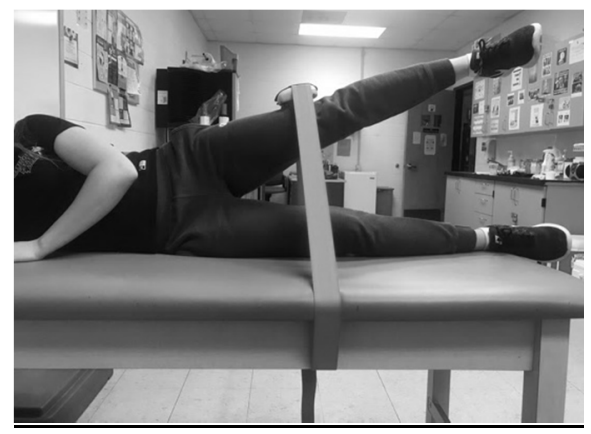

Figure 2. Hip abduction. The mobilization belt adjusted to $30^{\circ}$ of motion. Participant abducts. 


\section{CHAPTER IV: RESULTS}

There were no significant differences between the right $(p=0.785)$ and left $(p=0.237)$ hip strength ratio between participants with and without LBP. The left and right legs have their own strength ratio measurement created in order to identify bilateral differences in the participants with LBP (Table 2). Our results indicated that there was no relationship between the left and right leg for both LBP and Control groups. The force values for this study were converted to Newtons and then normalized to body mass using the following equation: (Normalized force= force/body mass $\left.{ }^{67}\right){ }^{15,89}$ (Table 3 )

Table 2 .

Strength Ratios

\begin{tabular}{|l|l|l|}
\hline & Right Ratio & Left Ratio \\
\hline LBP & $1.6 \pm 0.6$ & $1.9 \pm 0.5$ \\
\hline Control & $1.7 \pm 0.6$ & $1.6 \pm 0.6$ \\
\hline
\end{tabular}

Note. Table 2 shows the calculated strength ratio between the left and right legs for both muscle groups, between both groups.

\section{Table 3.}

Strength Value Average Normalized to Body Mass

\begin{tabular}{|l|l|l|l|l|}
\hline & L ABD Strength & L ADD Strength & R ABD Strength & R ADD Strength \\
\hline LBP & $13.2 \pm 2.8 \mathrm{~N}$ & $7.5 \pm 2.1 \mathrm{~N}$ & $13.4 \pm 2.9 \mathrm{~N}$ & $8.7 \pm 2.3 \mathrm{~N}$ \\
\hline Control & $13.1 \pm 2.1 \mathrm{~N}$ & $8.9 \pm 2.9 \mathrm{~N}$ & $13.6 \pm 2.4 \mathrm{~N}$ & $8.7 \pm 2.9 \mathrm{~N}$ \\
\hline
\end{tabular}

Note. Table 3 show the calculated force normalized to Body Mass for both muscle groups, on each leg, and between both groups. 


\section{CHAPTER V: DISCUSSION}

This study was performed to determine if the strength ratio measurements between healthy and LBP populations were different. For both groups, the hip abductor to hip adductor strength ratios were similar to one another. Although the LBP group was experiencing subjectively moderate pain and disability, hip musculature strength was not different between groups. Also, the results of this study did not demonstrate a muscular imbalance for LBP and the control groups; however, previous researchers have identified that hip musculature weakness does affect the occurrence of LBP.9,10,20,23,27

Researchers have suggested that hip adductors increase in strength and firing when injury occurs to the knee. ${ }^{29}$ Additionally, it has been established that with hip weakness, mainly of the hip abductors, there is an increased need for a patient to control the direction of the femur. ${ }^{68}$ This results in the hip adductors compensating by increasing femoral adduction to stabilize the body in stance and motion. ${ }^{29,68}$ Pertaining more to the hip abductors, these muscles can cause a cascade of effects to the body biomechanically that could cause LBP. Previous studies have shown that participants with LBP have weak abductor muscles on the affected side or both sides of pain. ${ }^{9,15}$ The weakness of the hip abductors causes the pelvis to drop ${ }^{15}$ and changes the way the innominate sits within the sacrum and the spine. ${ }^{59}$ This biomechanical change may cause LBP. The research conducted on the hip abductors for LBP has been extensive, with most concluding that strengthening exercises for the hip abductors is beneficial for treating those with LBP. $^{2-4,8,9,12,15,16,25,41,64,67}$ It is important for clinicians and researchers to be able to determine this strength ratio measurements of the hip abductors to the hip adductors to use as a rehabilitation tool in strengthening the hip musculature in patients with LBP. Knowing strengthening of the hip abductors is essential in treatment of LBP, the hip abductor to hip adductor strength ratio 
measurement calculated in this study may provide a clinical goal to reach in hip abductor strength for each patient.

In our study, the hip adductors did not show weakness. This may be due to the difference in participants, where weakness has been shown in older participant populations and did not use as strict inclusion criteria as this study. ${ }^{9,23}$ Additionally, these studies also observed LBP participants in a chronic state, whereas this study did not. For the reasons of having an athletic population and accepting participants that did not have chronic LBP, it is believed that hip abductor weakness in this study was not observed between the LBP and control groups. When comparing the strength value results for the hip abductors in this study compared to other studies, ${ }^{4,15,23,36}$ our study displayed higher strength values, by almost double. Due to the higher strength values of the hip abductors in our study, this group resembled the control group similar to other studies. ${ }^{4,15,23,36}$ It would appear that a normal strength ratio of the hip abductors to adductors would be greater than 1.0.

Research has yet to supply any type of strength ratio measurement between the hip adductors and hip abductors, and how this strength ratio may change in patient suffering with LBP. The strength ratio measurement for the control group in this study should be used as a clinical normative value for identifying a hip abductor to hip adductor strength ratio measure in a young, athletic population. Concurrently, it is believed that the strength ratio measurements created in the control group for this study, is a normative value that is applicable to all healthy populations.

\section{Limitations}

Some limitations to this study occur in the control of the setting and low level of disability on the ODI. Most of the participants recruited for the study were college-aged students 
and self-identified as physically active by performing physical activity at least three times a week (i.e., weight lifting, running, sports). This limited population pool affects the generalizability of the study. A limited age population may also affect the level of disability that was measured within the study. It may also be identifiable that participants with a higher range of disability could show a difference in strength ratios. Our population was classified as having non-specific LBP, suggesting they are not consulting with a physician or in severe pain to warrant physical therapy.

For future research, this study could be repeated with a participant population displaying higher disability, and weakness of the hip abductors. Future research should examine if other muscle imbalances may be associated with weakness of both the hip adductor muscles and hip abductors. This may help understand a fuller picture these muscles and their contribution to LBP.

\section{Conclusion}

While it is still unknown what the comparative effects of the hip abductors and adductors have during LBP, it is still vital for future research to identify the firing pattern and/or force production that the hip adductors present. A strength ratio measurement has been identified for the healthy control group between the hip abductors to hip adductors. This can be used to identify if any changes occur in participants with LBP. Determining appropriate muscle balance ratios and measuring differences is important for curating rehabilitation plans to enhance patient care. 


\section{REFERENCES}

1. Ehrlich GE. Low back pain. Bull World Health Organ. 2003;81(9):671-676.

2. Dillingham T. Evaluation and management of low back pain: an overview. State Arts Rev. 1995;9(3):559-574.

3. Evans KL, Hughes J, Williams MD. Reduced severity of lumbo-pelvic-hip injuries in professional Rugby Union players following tailored preventative programmes. J Sci Med Sport. July 2017. doi:10.1016/j.jsams.2017.07.004

4. Kendall KD, Emery CA, Wiley JP, Ferber R. The effect of the addition of hip strengthening exercises to a lumbopelvic exercise programme for the treatment of non-specific low back pain: A randomized controlled trial. J Sci Med Sport. 2015;18(6):626-631. doi:10.1016/j.jsams.2014.11.006

5. Hemborg B, Moritz U. Intra-abdominal pressure and trunk muscle activity during lifting. II. Chronic low-back patients. Scand J Rehabil Med. 1985;17(1):5-13.

6. Levine D, Walker JR, Tillman LJ. The effect of abdominal muscle strengthening on pelvic tilt and lumbar lordosis. Physiotherapy Theory and Practice. 1997;13(3):217-226. doi:10.3109/09593989709036465

7. Harris-Hayes M, Mueller MJ, Sahrmann SA, et al. Persons with chronic hip joint pain exhibit reduced hip muscle strength. J Orthop Sports Phys Ther. 2014;44(11):890-898. doi:10.2519/jospt.2014.5268

8. Ashmen K, Swanik C, Lephart S. Strength and flexibility characteristics of athletes with chronic low back pain. J Sport Rehabil. 1996;5(4):275-286. doi:10.1123/jsr.5.4.275

9. Cooper NA, Scavo KM, Strickland KJ, et al. Prevalence of gluteus medius weakness in people with chronic low back pain compared to healthy controls. Eur Spine J. 2016;25(4):12581265. doi:10.1007/s00586-015-4027-6

10. Nadler SF, Malanga GA, Feinberg JH, Prybicien M, Stitik TP, DePrince M. Relationship between hip muscle imbalance and occurrence of low back pain in collegiate athletes: a prospective study. Am J Phys Med Rehabil. 2001;80(8):572-577.

11. Helewa A, Goldsmith C, Smythe H, Gibson E. An evaluation of four different measures of abdominal muscle strength: patient, order and instrument variation. J Rheumatol. 1990;17(7):965-969.

12. Lee JH, Ooi Y, Nakamura K. Measurement of muscle strength of the trunk and the lower extremities in subjects with history of low back pain. Spine. 1995;20(18):1994-1996. 
13. McNeill T, Warwick D, Andersson G, Schultz A. Trunk strengths in attempted flexion, extension, and lateral bending in healthy subjects and patients with low-back disorders. Spine. 1980;5(6):529-538.

14. Nachemson A, Lindh M. Measurement of abdominal and back muscle strength with and without low back pain. Scand J Rehabil Med. 1969;1(2):60-63.

15. Kendall KD, Schmidt C, Ferber R. The relationship between hip-abductor strength and the magnitude of pelvic drop in patients with low back pain. J Sport Rehabil. 2010;19(4):422435 .

16. Alston W, Carlson KE, Feldman DJ, Grimm Z, Gerontinos E. A quantitative study of muscle factors in the chronic low back syndrome. J Am Geriatr Soc. 1966;14(10):1041-1047.

17. Mellin G. Correlations of hip mobility with degree of back pain and lumbar spinal mobility in chronic low-back pain patients. Spine. 1988;13(6):668-670.

18. Burton AK. Regional lumbar sagittal mobility; measurement by flexicurves. Clin Biomech (Bristol, Avon). 1986;1(1):20-26. doi:10.1016/0268-0033(86)90032-X

19. Lankhorst GJ, Van de Stadt RJ, Van der Korst JK. The natural history of idiopathic low back pain. A three-year follow-up study of spinal motion, pain and functional capacity. Scand $J$ Rehabil Med. 1985;17(1):1-4.

20. Hellsing AL. Tightness of hamstring- and psoas major muscles. A prospective study of back pain in young men during their military service. Ups J Med Sci. 1988;93(3):267-276.

21. Toppenberg RM, Bullock MI. The interrelation of spinal curves, pelvic tilt and muscle lengths in the adolescent female. Aust J Physiother. 1986;32(1):6-12. doi:10.1016/S00049514(14)60638-3

22. Youdas JW, Garrett TR, Harmsen S, Suman VJ, Carey JR. Lumbar lordosis and pelvic inclination of asymptomatic adults. Phys Ther. 1996;76(10):1066-1081.

23. Nourbakhsh MR, Arab AM. Relationship between mechanical factors and incidence of low back pain. J Orthop Sports Phys Ther. 2002;32(9):447-460. doi:10.2519/jospt.2002.32.9.447

24. Brandt M, Jakobsen MD, Thorborg K, Sundstrup E, Jay K, Andersen LL. Perceived loading and muscle activity during hip strengthening exercises: comparison of elastic resistance and machine exercises. Int J Sports Phys Ther. 2013;8(6):811-819.

25. Hayden JA, van Tulder MW, Malmivaara AV, Koes BW. Meta-analysis: exercise therapy for nonspecific low back pain. Ann Intern Med. 2005;142(9):765-775. 
26. Park RJ, Tsao H, Cresswell AG, Hodges PW. Changes in direction-specific activity of psoas major and quadratus lumborum in people with recurring back pain differ between muscle regions and patient groups. J Electromyogr Kinesiol. 2013;23(3):734-740. doi:10.1016/j.jelekin.2013.01.010

27. Lee JH, Hoshino Y, Nakamura K, Kariya Y, Saita K, Ito K. Trunk muscle weakness as a risk factor for low back pain. A 5-year prospective study. Spine. 1999;24(1):54-57.

28. Cailliet R, Cailliet R. Low Back Pain Syndrome. Ed. 5. Philadelphia: F.A. Davis; 1995.

29. Niemuth PE, Johnson RJ, Myers MJ, Thieman TJ. Hip muscle weakness and overuse injuries in recreational runners. Clin J Sport Med. 2005;15(1):14-21.

30. Rafn BS, Tang L, Nielsen MP, Branci S, Hölmich P, Thorborg K. Hip Strength Testing of Soccer Players With Long-Standing Hip and Groin Pain: What are the Clinical Implications of Pain During Testing? Clin J Sport Med. 2016;26(3):210-215. doi:10.1097/JSM.0000000000000227

31. Hrysomallis C. Hip adductors' strength, flexibility, and injury risk. J Strength Cond Res. 2009;23(5):1514-1517. doi:10.1519/JSC.0b013e3181a3c6c4

32. Levangie P, Norkin C. Joint Structure and Function: A Comprehensive Analysis. 4th ed. Philadelphia, PA: F.A Davis Company; 2005.

33. Leighton RD. A functional model to describe the action of the adductor muscles at the hip in the transverse plane. Physiother Theory Pract. 2006;22(5):251-262. doi:10.1080/09593980600927385

34. Mann RA, Moran GT, Dougherty SE. Comparative electromyography of the lower extremity in jogging, running, and sprinting. Am J Sports Med. 1986;14(6):501-510. doi: $10.1177 / 036354658601400614$

35. Montgomery WH, Pink M, Perry J. Electromyographic analysis of hip and knee musculature during running. Am J Sports Med. 1994;22(2):272-278. doi:10.1177/036354659402200220

36. Hides JA, Oostenbroek T, Franettovich Smith MM, Mendis MD. The effect of low back pain on trunk muscle size/function and hip strength in elite football (soccer) players. $J$ Sports Sci. 2016;34(24):2303-2311. doi:10.1080/02640414.2016.1221526

37. Hoppenfeld S, Hutton R. Physical Examination of the Spine and Extremities. New York: Appleton-Century-Crofts; 1976.

38. Gray H, Clemente CD. Anatomy of the Human Body. 30th American ed. Philadelphia: Lea \& Febiger; 1985.

39. Marieb EN, Hoehn K. Human Anatomy \& Physiology. Tenth edition. Boston: Pearson; 2016. 
40. Koulouris G, Connell D. Hamstring Muscle Complex: An Imaging Review. RadioGraphics. 2005;25(3):571-586. doi:10.1148/rg.253045711

41. Starkey C, Brown SD. Examination of Orthopedic \& Athletic Injuries.; 2015.

42. Violante FS, Mattioli S, Bonfiglioli R. Low-back pain. Handb Clin Neurol. 2015;131:397410. doi:10.1016/B978-0-444-62627-1.00020-2

43. Pengel LHM, Herbert RD, Maher CG, Refshauge KM. Acute low back pain: systematic review of its prognosis. BMJ. 2003;327(7410):323. doi:10.1136/bmj.327.7410.323

44. Stanton TR, Henschke N, Maher CG, Refshauge KM, Latimer J, McAuley JH. After an episode of acute low back pain, recurrence is unpredictable and not as common as previously thought. Spine. 2008;33(26):2923-2928. doi:10.1097/BRS.0b013e31818a3167

45. Knecht C, Humphreys BK, Wirth B. An Observational Study on Recurrences of Low Back Pain During the First 12 Months After Chiropractic Treatment. J Manipulative Physiol Ther. 2017;40(6):427-433. doi:10.1016/j.jmpt.2017.03.005

46. Fritz JM. Clinical prediction rules in physical therapy: coming of age? J Orthop Sports Phys Ther. 2009;39(3):159-161. doi:10.2519/jospt.2009.0110

47. Hicks GE, Fritz JM, Delitto A, McGill SM. Preliminary development of a clinical prediction rule for determining which patients with low back pain will respond to a stabilization exercise program. Arch Phys Med Rehabil. 2005;86(9):1753-1762. doi:10.1016/j.apmr.2005.03.033

48. Hebert J, Koppenhaver S, Fritz J, Parent E. Clinical prediction for success of interventions for managing low back pain. Clin Sports Med. 2008;27(3):463-479, ix-x. doi:10.1016/j.csm.2008.03.002

49. Hebert JJ, Fritz JM. Clinical decision rules, spinal pain classification and prediction of treatment outcome: A discussion of recent reports in the rehabilitation literature. Chiropr Man Therap. 2012;20(1):19. doi:10.1186/2045-709X-20-19

50. Walker ML, Rothstein JM, Finucane SD, Lamb RL. Relationships between lumbar lordosis, pelvic tilt, and abdominal muscle performance. Phys Ther. 1987;67(4):512-516.

51. Nadler SF, Malanga GA, DePrince M, Stitik TP, Feinberg JH. The relationship between lower extremity injury, low back pain, and hip muscle strength in male and female collegiate athletes. Clin J Sport Med. 2000;10(2):89-97.

52. Hides JA, Lambrecht G, Stanton WR, Damann V. Changes in multifidus and abdominal muscle size in response to microgravity: possible implications for low back pain research. Eur Spine J. 2016;25 Suppl 1:175-182. doi:10.1007/s00586-015-4311-5

53. Day JW, Smidt GL, Lehmann T. Effect of pelvic tilt on standing posture. Phys Ther. 1984;64(4):510-516. 
54. Youdas JW, Garrett TR, Egan KS, Therneau TM. Lumbar lordosis and pelvic inclination in adults with chronic low back pain. Phys Ther. 2000;80(3):261-275.

55. Jorgensson A. The iliopsoas muscle and the lumbar spine. Aust J Physiother. 1993;39(2):125-132. doi:10.1016/S0004-9514(14)60477-3

56. Sadler SG, Spink MJ, Ho A, De Jonge XJ, Chuter VH. Restriction in lateral bending range of motion, lumbar lordosis, and hamstring flexibility predicts the development of low back pain: a systematic review of prospective cohort studies. BMC Musculoskelet Disord. 2017;18(1):179. doi:10.1186/s12891-017-1534-0

57. van Wingerden J, Vleeming A, Kleinrensink G, Stoeckart R. The role of the hamstrings in pelvic and spinal function. New York: Churchill Livingstone. 1997:207-210.

58. Leino P, Aro S, Hasan J. Trunk muscle function and low back disorders: a ten-year follow-up study. J Chronic Dis. 1987;40(4):289-296.

59. Wong TKT, Lee RYW. Effects of low back pain on the relationship between the movements of the lumbar spine and hip. Hum Mov Sci. 2004;23(1):21-34. doi:10.1016/j.humov.2004.03.004

60. Roy SH, De Luca CJ, Casavant DA. Lumbar muscle fatigue and chronic lower back pain. Spine. 1989;14(9):992-1001.

61. Hultman G, Nordin M, Saraste H, Ohlsèn H. Body composition, endurance, strength, crosssectional area, and density of MM erector spinae in men with and without low back pain. $J$ Spinal Disord. 1993;6(2):114-123.

62. Biering-Sørensen F. Physical measurements as risk indicators for low-back trouble over a one-year period. Spine. 1984;9(2):106-119.

63. Wilder DG, Aleksiev AR, Magnusson ML, Pope MH, Spratt KF, Goel VK. Muscular response to sudden load. A tool to evaluate fatigue and rehabilitation. Spine. 1996;21(22):2628-2639.

64. Janda V, Jull G. Muscles and Motor Control In Low Back Pain: Assessment. Physical Therapy of the Low Back. 1987.

65. Hultman G, Saraste H, Ohlsen H. Anthropometry, spinal canal width, and flexibility of the spine and hamstring muscles in 45-55-year-old men with and without low back pain. $J$ Spinal Disord. 1992;5(3):245-253.

66. Troup JD, Foreman TK, Baxter CE, Brown D. 1987 Volvo award in clinical sciences. The perception of back pain and the role of psychophysical tests of lifting capacity. Spine. 1987;12(7):645-657. 
67. Macadam P, Cronin J, Contreras B. AN EXAMINATION OF THE GLUTEAL MUSCLE ACTIVITY ASSOCIATED WITH DYNAMIC HIP ABDUCTION AND HIP EXTERNAL ROTATION EXERCISE: A SYSTEMATIC REVIEW. Int J Sports Phys Ther. 2015;10(5):573-591.

68. Ireland ML, Willson JD, Ballantyne BT, Davis IM. Hip strength in females with and without patellofemoral pain. J Orthop Sports Phys Ther. 2003;33(11):671-676. doi:10.2519/jospt.2003.33.11.671

69. Steindler A. Kinesiology of the Human Body under Normal and Pathological Conditions. Charles C Thomas Publisher; 1955.

70. Baltzopoulos V, Brodie DA. Isokinetic dynamometry. Applications and limitations. Sports Med. 1989;8(2):101-116.

71. Kannus P. Isokinetic evaluation of muscular performance: implications for muscle testing and rehabilitation. Int J Sports Med. 1994;15 Suppl 1:S11-18. doi:10.1055/s-2007-1021104

72. Coombs R, Garbutt G. Developments in the use of the hamstring/quadriceps ratio for the assessment of muscle balance. J Sports Sci Med. 2002;1(3):56-62.

73. Keegan JJ. Alterations of the lumbar curve related to posture and seating. J Bone Joint Surg Am. 1953;35-A(3):589-603.

74. Mohammad WS, Abdelraouf OR, Elhafez SM, Abdel-Aziem AA, Nassif NS. Isokinetic imbalance of hip muscles in soccer players with osteitis pubis. Journal of Sports Sciences. 2014;32(10):934-939. doi:10.1080/02640414.2013.868918

75. During J, Goudfrooij H, Keessen W, Beeker TW, Crowe A. Toward standards for posture. Postural characteristics of the lower back system in normal and pathologic conditions. Spine. 1985;10(1):83-87.

76. Gautier J, Morillon P, Marcelli C. Does spinal morphology influence the occurrence of low back pain? A retrospective clinical, anthropometric, and radiological study. Rev Rhum Engl Ed. 1999;66(1):29-34.

77. Hansson T, Bigos S, Beecher P, Wortley M. The lumbar lordosis in acute and chronic lowback pain. Spine. 1985;10(2):154-155.

78. Endo K, Suzuki H, Sawaji Y, et al. Relationship among cervical, thoracic, and lumbopelvic sagittal alignment in healthy adults. J Orthop Surg (Hong Kong). 2016;24(1):92-96. doi:10.1177/230949901602400121

79. Amonoo-Kuofi HS. Changes in the lumbosacral angle, sacral inclination and the curvature of the lumbar spine during aging. Acta Anat (Basel). 1992;145(4):373-377.

80. Christie HJ, Kumar S, Warren SA. Postural aberrations in low back pain. Arch Phys Med Rehabil. 1995;76(3):218-224. 
81. Andersson GB. Epidemiological features of chronic low-back pain. Lancet. 1999;354(9178):581-585. doi:10.1016/S0140-6736(99)01312-4

82. Friberg O. Clinical symptoms and biomechanics of lumbar spine and hip joint in leg length inequality. Spine. 1983;8(6):643-651.

83. Cummings G, Scholz JP, Barnes K. The effect of imposed leg length difference on pelvic bone symmetry. Spine. 1993;18(3):368-373.

84. Hoikka V, Ylikoski M, Tallroth K. Leg-length inequality has poor correlation with lumbar scoliosis. A radiological study of 100 patients with chronic low-back pain. Arch Orthop Trauma Surg. 1989;108(3):173-175.

85. Jackson SM, Cheng MS, Smith AR, Kolber MJ. Intrarater reliability of hand held dynamometry in measuring lower extremity isometric strength using a portable stabilization device. Musculoskelet Sci Pract. 2017;27:137-141. doi:10.1016/j.math.2016.07.010

86. Ieiri A, Tushima E, Ishida K, Inoue M, Kanno T, Masuda T. Reliability of measurements of hip abduction strength obtained with a hand-held dynamometer. Physiotherapy Theory and Practice. 2015;31(2):146-152. doi:10.3109/09593985.2014.960539

87. Thorborg K, Petersen J, Magnusson SP, Hölmich P. Clinical assessment of hip strength using a hand-held dynamometer is reliable. Scand J Med Sci Sports. 2010;20(3):493-501. doi:10.1111/j.1600-0838.2009.00958.x

88. Delmore RJ, Laudner KG, Torry MR. Adductor longus activation during common hip exercises. J Sport Rehabil. 2014;23(2):79-87. doi:10.1123/jsr.2012-0046

89. Bazett-Jones DM, Cobb SC, Joshi MN, Cashin SE, Earl JE. Normalizing hip muscle strength: establishing body-size-independent measurements. Arch Phys Med Rehabil. 2011;92(1):76-82. doi:10.1016/j.apmr.2010.08.020

90. Fairbank JC, Pynsent PB. The Oswestry Disability Index. Spine. 2000;25(22):2940-2952; discussion 2952.

91. Fairbank J, Pynsent P. Oswestry Low Back Pain Disability Questionnaire. In: The Oswestry Disability Index. Vol 22. Spine; 2000:2940-2953.

92. Fairbank JCT. Oswestry disability index. J Neurosurg Spine. 2014;20(2):239-241. doi:10.3171/2013.7.SPINE13288

93. Huskisson EC. Measurement of pain. Lancet. 1974;2(7889):1127-1131.

94. Copay AG, Glassman SD, Subach BR, Berven S, Schuler TC, Carreon LY. Minimum clinically important difference in lumbar spine surgery patients: a choice of methods using the Oswestry Disability Index, Medical Outcomes Study questionnaire Short Form 36, and pain scales. Spine J. 2008;8(6):968-974. doi:10.1016/j.spinee.2007.11.006 
95. Kelly AM. Does the clinically significant difference in visual analog scale pain scores vary with gender, age, or cause of pain? Acad Emerg Med. 1998;5(11):1086-1090.

96. Hislop HJ, Avers D, Brown M, Daniels L. Daniels and Worthingham's Muscle Testing: Techniques of Manual Examination and Performance Testing. 9th ed. St. Louis, Mo: Elsevier; 2014.

97. Teyhen DS, Miltenberger CE, Deiters HM, et al. The use of ultrasound imaging of the abdominal drawing-in maneuver in subjects with low back pain. J Orthop Sports Phys Ther. 2005;35(6):346-355. doi:10.2519/jospt.2005.35.6.346 